\title{
Efecto de los niveles de proteína sobre el desempeño de codornices japonesas en fase de postura
}

\author{
The effect of protein level on egg-laying Japanese quails \\ Efeito dos níveis de proteína sobre o desempenho de codornas \\ japonesas na fase de postura
}

Víctor L. Hurtado - Nery ${ }^{1 *}$, Diana M. Torres - Novoa ${ }^{2 *}$, Álvaro Ocampo - Durán ${ }^{3 *}$

Médico Veterinário Zootecnista, PhD, MSc.
Médico Veterinário Zootecnista, MSc
Zootecnista, PhD, MSc.
Grupo de investigación en Sistemas Sostenibles de producción
Escuela de Medicina Veterinaria y Zootecnia Universidad de los Llanos
Email: johnnie182@hotmail.com

Recibido: agosto 31 de $2011 \quad$ Aceptado: marzo 12 de 2013

\begin{abstract}
Resumen
Con el objetivo de determinar el nivel óptimo de proteína bruta en codornices japonesas en fase de postura, fue realizado este trabajo en la sección de codornices de la Universidad de los Llanos. Fueron utilizadas 480 codornices de 34 días de edad, distribuidas en un diseño experimental completamente al azar, en un arreglo factorial de $4 \times 4$, cuatro niveles de proteína $(17,5 ; 19,0 ; 20,5$ y $22,0 \%)$ y cuatro niveles de energía metabolizable $(2750,2850,2950$ y $3050 \mathrm{k}$ cal EM/kg), con tres repeticiones y 10 aves por repetición, para un total de 48 unidades experimentales. Los resultados fueron procesados en el programa SAEG. Los resultados no arrojaron interacción entre los niveles de proteína y energía. Los niveles de proteína influyeron de forma cuadrática sobre la producción de huevos, conversión alimenticia (kg de ración/docenas de huevos y $\mathrm{kg}$ de ración/ $\mathrm{kg}$ de huevo) y de forma linear sobre el peso del huevo. El tratamiento con mayor postura (91\%) se obtuvo con $20,5 \%$ de proteína bruta y 2750 k cal de EM/kg. En conclusión, el desarrollo de la ecuación de regresión permite estimar en $19,16 \%$ el requerimiento de proteína bruta para máxima producción de huevos
\end{abstract}

Palabras Clave: Codornices, producción de huevos, requerimientos nutricionales.

\begin{abstract}
This work was carried out at the Universidad de the Llanos' quail section for determining the optimum crude protein (CP) level for Japanese quail during their egg-laying phase. Four hundred and eighty 34-day-old quail were used, distributed in a completely random experimental design, using a 4x4 factorial arrangement, four protein levels (17.5, 19.0, 20.5 and $22.0 \%$ ) and four metabolisable energy (ME) levels $(2,750,2,850,2,950$ and 3,050 k lime ME/kg), with three repeats and 10 birds per repetition, giving a total of 48 experimental units. SAEG software was used for processing the results. The results did not suggest any interaction between protein and energy levels. Protein level had a quadratic effect on egg production and feed conversion ( $\mathrm{kg}$ ration/dozen eggs and $\mathrm{kg}$ ration/ $\mathrm{kg}$ egg) and a linear effect on egg weight. The treatment resulting in the greatest egg-laying (91\%) was obtained with $20.5 \% \mathrm{CP}$ and $2,750 \mathrm{k}$ lime ME/kg. The regression equation thus led to estimating a $19.16 \% \mathrm{CP}$ requirement for maximum egg production in Japanese quails.
\end{abstract}


Key words: quail, egg production, nutritional requirement.

\begin{abstract}
Resumo
Com o objetivo de determinar o nível ótimo de proteína bruta em codornas japonesas na fase de postura, foi realizado este trabalho na seção de codornas da Universidade de los Llanos. Foram utilizados 480 codornas de 34 dias de idade, distribuídas em um delineamento experimental inteiramente casualizado, em esquema fatorial 4x4, quatro níveis de proteína (17,5, 19,0, 20,5 e 22,0\%) e quatro níveis de energia metabolizável (2750, 2850, 2950 e 3050 k cal ME / kg), com três repetições e 10 aves por repetição, para um total de 48 unidades experimentais. Os resultados foram processados no programa SAEG. Os resultados não apresentaram interação entre os níveis de proteína e de energia. Os níveis de proteína influenciaram de modo quadrático sobre a produção de ovos, conversão alimentar (kg de ração / dúzia de ovos e kg de ração / kg de ovos) e de forma linear sobre o peso do ovo. O tratamento com maior postura (91\%) foi obtido com 20,5\% de proteína bruta e 2750 k cal de ME / kg. Em conclusão, o desenvolvimento da equação de regressão permite estimar em 19,16\% a exigência de proteína bruta para máxima produção máxima de ovos
\end{abstract}

Palavras chave: codornas, produção de ovos, exigências nutricionais.

\section{Introducción}

La producción de codornices ha sido considerada una actividad alternativa para pequeños productores. Sin embargo el potencial de producción de huevos y carne reportado en los últimos años ha estimulado su explotación comercial (Murakami y García, 2007), como es el caso de Colombia que durante 2009 produjo 9.681.735 huevos y consumo per cápita de 111 gramos, cuya producción se concentra $(83,7 \%)$ en la región central, Santander y el Valle, entretanto, la producción mundial entre 2006 y 2009 fue estimada en 58.000 millones de huevos (Flórez y Ospina, 2010)

En la composición de los costos totales de producción cerca del 65 al 70\% corresponde a la ración, en la cual la proteína es responsable de aproximadamente 25\% (Silva y Ribeiro, 2001).

Los valores de proteína bruta y energía metabolizable utilizados en la alimentación de codornices son contrastantes, $18 \%$ de proteína bruta y 2.585 k cal de EM/ kg, según Freitas et al., 2005;22,42\% de PB y 2.850 k cal de EM/ kg de ración, según Pinto et al., 2002. Costa et al., (2008), utilizando una ración basada en maíz y soya con $19,9 \%$ PB y diferentes niveles de lisina, obtuvieron $90,8 \%$ de postura, 12,4 gramos de peso de los huevos y conversión alimenticia de 2,52.

Los diferentes valores de proteína bruta y de energía metabolizable dependen de las materias primas utilizadas, las condiciones experimentales, edad de las aves, línea genética de los animales, granulometría y procesamiento de los ingredientes (Penz Jr. et al., 1999), entre otros factores que pueden interferir en la evaluación de los nutrientes de los alimentos.

La energía metabolizable es una propiedad estratégica nutricional en sistemas de cría con alimentación a vo- luntad, debido a que el consumo de ración es regulado principalmente por la densidad calórica de la dieta y puede determinar la eficiencia productiva y económica de la actividad (Moura et al., 2010).

Establecer los requerimientos de proteína bruta y energía metabolizable para codornices japonesas en postura en condiciones de clima caliente, contribuirá para formular raciones con las cantidades necesarias de esos nutrientes, para optimizar la producción de huevos (80-84\% Rizzo et al., 2008) evitando el exceso de los mismos en la dieta, que posteriormente serán eliminados a través de las heces.

Este trabajo fue realizado con el objetivo de determinar el nivel óptimo de proteína bruta para codornices en fase de postura en condiciones tropicales utilizando alimentos convencionales.

\section{Materiales y métodos}

Este trabajo fue realizado en la sección de codornices de la Granja de la Universidad de los Llanos, sede Barcelona, en el municipio de Villavicencio, con temperatura de $27^{\circ} \mathrm{C}$, humedad relativa de $85 \%$, precipitación anual de $3500 \mathrm{~mm}$ y una altitud de $423 \mathrm{msnm}$, ubicado a $74^{\circ} 4^{\prime} 30^{\prime \prime}$ de longitud oeste, $4^{\circ} 35^{\prime} 57^{\prime \prime}$ de latitud norte (IGAC, 2007).

Se utilizaron 480 codornices de 34 días de edad y $94,9 \pm 12,5 \mathrm{~g}$ de peso inicial, distribuidas en un diseño experimental completamente al azar, con 16 tratamientos, con tres repeticiones por tratamiento y 10 aves por repetición, en un arreglo factorial de $4 \times 4$, cuatro niveles de energía metabolizable (2750, 2850, 2950 y 3050 k cal EM/kg) y cuatro niveles de proteína bruta $(17,5,19,0,20,5$, y $22,0 \%)$ para un total de 48 unidades experimentales. Fueron suministradas 14 
horas de luz natural y artificial al día durante la fase experimental que tuvo una duración de 24 semanas.

Las aves fueron alojadas en jaulas de alambre, en módulos de cinco pisos y tres divisiones por piso de $40 \times 40 \mathrm{~cm}$, dotadas de comederos y bebederos automáticos tipo copa.

Las dietas experimentales (tabla 1) fueron elaboradas con maíz, torta de soya, mogolla de trigo, fosfato bicálcico, carbonato de calcio, aceite vegetal, premezcla vitamínico-mineral, sal, L-lisina, DL-metionina, antioxidante y material inerte, para atender los requerimientos nutricionales para codornices en fase de postura (NRC, 1994), excepto para proteína bruta e energía metabolizable. La composición nutricional de los ingredientes utilizados en la ración fue determinada en el Laboratorio de Nutrición Animal de la Universidad de los Llanos.

El manejo diario de los animales incluía las siguientes actividades: la ración y el agua fueron suministrados a voluntad, las sobras de alimento en los comederos fueron recolectadas y pesadas en horas de la mañana, para establecer por diferencia el consumo diario de ración. Del mismo, fue monitoreada la temperatura interna del galpón.

Las heces fueron recolectadas diariamente y sometidas a compostaje para evitar deterioro ambiental y posterior utilización del compost en actividades agrícolas.

Las aves fueron monitoreadas diariamente en su estado sanitario, los eventuales casos de mortalidad eran retirados y depositados en el compost. Los casos de mortalidad sometidos al examen de patología no fue constada entidad infecciosa.

La producción de huevos era recolectada en las horas de la mañana, la cual era pesada y acondicionada en cubetas plásticas, para facilitar la manipulación, almacenamiento, transporte y conservación de los huevos.

La producción, el peso del huevo y el suministro de ración por unidad experimental, fueron registrados diariamente en instrumentos diseñados para tal fin.

Los datos fueron recolectados diariamente en instrumentos diseñados para tal fin y tabulados posteriormente en planillas electrónicas y procesados estadísticamente en el programa SAEG 8.1, sometidos a análisis de varianza y de regresión polinomial.

\section{Resultados}

Durante la fase experimental la temperatura mínima y máxima diaria fue de $25,1 \pm 3,0$ y $30,4 \pm 1,4^{\circ} \mathrm{C}$., respecti- vamente, valores que se ubican por encima del rango de termoneutralidad para las codornices.

En la tabla 2 se presentan los resultados de producción de huevos, consumo diario de ración, peso del huevo y conversión alimenticia de codornices japonesas alimentadas con raciones con diferentes niveles de proteína bruta y de energía metabolizable, donde se observa que no hubo interacción significativa $(p>0,05)$ entre los niveles de PB y EM para las variables en estudio, es decir los factores actuaron de manera independiente.

Al análisis de regresión, los niveles de proteína influenciaron de forma linear $(p<0,05)$ el peso del huevo de y de forma cuadrática la producción de huevos, la conversión alimenticia relacionada con kg de ración/docena de huevos y $\mathrm{kg}$ de ración/kg de huevo.

Los niveles de proteína y de energía no influyeron en el consumo diario de ración $(p>0,05)$, sugiriendo que los nutrientes contenidos en las raciones son suficientes para atender las funciones de producción y mantenimiento de las aves.

El tratamiento con mayor postura se obtuvo con $20,5 \%$ de proteína bruta y la menor producción de huevos se presentó con $22 \%$ de PB. El desarrollo de la ecuación de regresión permite estimar en 19,16\% el requerimiento de proteína bruta para máxima producción de huevos (figura 1).

La cantidad de proteína bruta en la ración influye $(p<0,05)$ en el peso de los huevos de forma linear, según la ecuación y $=0,1193 x+7,7707$ $\mathrm{R}^{2}=74,3$ (Figura 2).

Los huevos más pesados se obtu eron con el tratamiento con $22 \%$ de PB y 3050 cal EM. El peso promedio del huevo de los tratamiє itos con $22 \%$ de proteína bruta y diferentes niveles d EM, fue superior a los demás tratamientos.

La conversión alimenticia relacionac con el consumo medio de ración por docena de $\mathrm{h}$ evos producidos ( $\mathrm{kg} /$ docena de huevos) fue influenci to de forma cuadrática (figura 3), por los niveles de F i, el desarrollo de la ecuación de regresión permite est nar en 19,75\% el requerimiento de PB para mejor Cc versión alimenticia relacionada con kg de ración / c 'cena de huevos, para codornices japonesas en fase c postura.

La conversión alimenticia relacionad con kg de ración / $\mathrm{kg}$ de huevo producido $(\mathrm{kg} / \mathrm{kg})$ o r asa de huevo fue influenciada de forma cuadrática por el nivel de proteína, la derivación de la ecuación de regresión permite 
Tabla 1. Composición centesimal de las raciones experimentales

\begin{tabular}{|c|c|c|c|c|c|c|c|c|}
\hline \multirow{2}{*}{ Ingrediente } & \multicolumn{4}{|c|}{ Proteína Bruta 17,5\% } & \multicolumn{4}{|c|}{ Proteína Bruta 19,0\% } \\
\hline & $2750^{*}$ & $2850^{*}$ & $2950^{*}$ & $3050^{*}$ & $2750^{*}$ & $2850^{*}$ & $2950^{*}$ & $3050^{*}$ \\
\hline Maíz & 55,000 & 55,000 & 55,000 & 55,000 & 50,500 & 50,500 & 50,500 & 50,500 \\
\hline T de soya & 26,880 & 26,880 & 26,880 & 26,880 & 31,010 & 31,010 & 31,010 & 31,010 \\
\hline Fosfato & 1,366 & 1,376 & 1,376 & 1,376 & 1,300 & 1,300 & 1,300 & 1,300 \\
\hline Carbonato & 5,410 & 5,400 & 5,400 & 5,400 & 5,430 & 5,430 & 5,430 & 5,430 \\
\hline Mogolla trigo & 5,000 & 5,000 & 5,000 & 5,000 & 5,000 & 5,000 & 5,000 & 5,000 \\
\hline Aceite & 1,480 & 2,600 & 3,730 & 4,860 & 2,020 & 3,160 & 4,290 & 5,442 \\
\hline VITAMIX & 0,500 & 0,500 & 0,500 & 0,500 & 0,500 & 0,500 & 0,500 & 0,500 \\
\hline Sal & 0,500 & 0,500 & 0,500 & 0,500 & 0,500 & 0,500 & 0,500 & 0,500 \\
\hline L-lisina & 0,245 & 0,245 & 0,245 & 0,245 & 0,124 & 0,124 & 0,124 & 0,124 \\
\hline DL Meti & 0,203 & 0,203 & 0,203 & 0,203 & 0,184 & 0,184 & 0,184 & 0,184 \\
\hline Treonina & 0,000 & 0,000 & 0,000 & 0,000 & 0,000 & 0,000 & 0,000 & 0,000 \\
\hline BHT & 0,01 & 0,01 & 0,01 & 0,01 & 0,01 & 0,01 & 0,01 & 0,01 \\
\hline Inerte & 3,406 & 2,286 & 1,156 & 0,026 & 3,422 & 2,282 & 1,152 & 0,00 \\
\hline \multirow{2}{*}{ Ingrediente } & \multicolumn{4}{|c|}{ Proteína Bruta 20,5\% } & \multicolumn{4}{|c|}{ Proteína Bruta 22,0\% } \\
\hline & $2750^{*}$ & $2850^{*}$ & $2950^{*}$ & $3050^{*}$ & $2750^{\star}$ & $2850^{*}$ & $2950^{*}$ & $3050^{*}$ \\
\hline Maíz & 46,000 & 46,000 & 46,000 & 46,000 & 41,000 & 41,000 & 41,000 & 41,000 \\
\hline T de soya & 35,140 & 35,140 & 35,140 & 35,140 & 39,360 & 39,360 & 39,360 & 39,360 \\
\hline Fosfato & 1,260 & 1,260 & 1,260 & 1,260 & 1,240 & 1,240 & 1,240 & 1,240 \\
\hline Carbonato & 5,440 & 5,440 & 5,440 & 5,440 & 5,430 & 5,430 & 5,430 & 5,430 \\
\hline Mogolla trigo & 5,000 & 5,000 & 5,000 & 5,000 & 5,000 & 5,000 & 5,000 & 5,000 \\
\hline Aceite & 2,600 & 3,720 & 4,840 & 5,970 & 3,310 & 4,440 & 5,570 & 6,700 \\
\hline VITAMIX & 0,500 & 0,500 & 0,500 & 0,500 & 0,500 & 0,500 & 0,500 & 0,500 \\
\hline Sal & 0,500 & 0,500 & 0,500 & 0,500 & 0,500 & 0,500 & 0,500 & 0,500 \\
\hline L-lisina & 0,010 & 0,010 & 0,010 & 0,010 & 0,000 & 0,000 & 0,000 & 0,000 \\
\hline DL Meti & 0,166 & 0,166 & 0,166 & 0,166 & 0,148 & 0,148 & 0,148 & 0,148 \\
\hline BHT & 0,01 & 0,01 & 0,01 & 0,01 & 0,01 & 0,01 & 0,01 & 0,01 \\
\hline Inerte & 3,374 & 2,254 & 1,134 & 0,004 & 3,502 & 2,372 & 1,242 & 0,112 \\
\hline
\end{tabular}

* $\mathrm{k} \mathrm{cal} \mathrm{EM/kg}$ 
Tabla 2. Desempeño zootécnico de codornices alimentadas con raciones conteniendo diferentes niveles de proteína bruta y de energía metabolizable.

\begin{tabular}{|c|c|c|c|c|c|c|}
\hline Proteína, \% & $\begin{array}{l}\text { Energía } \\
\mathrm{kcal} / \mathrm{kg}\end{array}$ & $\begin{array}{c}\text { Postura }{ }^{1} \text {, } \\
\%\end{array}$ & $\begin{array}{c}\text { Peso del } \\
\text { huevo }^{2} \text {, } \\
\text { g }\end{array}$ & $\begin{array}{c}\text { Consumo } \\
\text { de ración, } \\
\mathrm{g}\end{array}$ & $\begin{array}{l}\text { Conversión } \\
\text { alimenticia } \\
\text { Docena }^{3} \text { kg }\end{array}$ & $\begin{array}{c}\text { masa de huevo } \\
\mathrm{kg} / \mathrm{kg}\end{array}$ \\
\hline \multirow{4}{*}{17,5} & 2750 & 84,97 & 10,2 & 23,8 & 0,410 & 3,376 \\
\hline & 2850 & 89,26 & 9,9 & 22,7 & 0,341 & 2,893 \\
\hline & 2950 & 78,20 & 9,7 & 24,0 & 0,419 & 3,604 \\
\hline & 3050 & 79,13 & 9,7 & 24,1 & 0,467 & 4,266 \\
\hline \multirow{4}{*}{19,0} & 2750 & 85,65 & 10,3 & 24,9 & 0,391 & 3,224 \\
\hline & 2850 & 84,08 & 9,5 & 24,0 & 0,414 & 3,693 \\
\hline & 2950 & 83,30 & 10,5 & 23,2 & 0,400 & 3,171 \\
\hline & 3050 & 79,76 & 10,1 & 22,4 & 0,348 & 2,852 \\
\hline \multirow{4}{*}{20,5} & 2750 & 91,00 & 9,9 & 24,0 & 0,338 & 2,870 \\
\hline & 2850 & 84,69 & 10,2 & 23,7 & 0,370 & 2,986 \\
\hline & 2950 & 82,25 & 10,0 & 22,6 & 0,403 & 3,448 \\
\hline & 3050 & 79,05 & 10,0 & 22,2 & 0,366 & 2,927 \\
\hline \multirow{4}{*}{22,0} & 2750 & 77,77 & 10,5 & 24,1 & 0,426 & 3,383 \\
\hline & 2850 & 85,52 & 10,5 & 23,5 & 0,368 & 2,900 \\
\hline & 2950 & 82,16 & 10,4 & 23,6 & 0,403 & 3,363 \\
\hline & 3050 & 79,23 & 10,6 & 23,6 & 0,440 & 3,577 \\
\hline \multicolumn{2}{|c|}{ Coeficiente de Variación } & 5,27 & 3,55 & 5,57 & 11,94 & 13,15 \\
\hline
\end{tabular}

1 Efecto cuadrático, $y=-0,0038 x^{2}+0,1456 x-0,5771, R^{2}=75,7$

2 Efecto linear, $y=0.1193 x+7.7707, R^{2}=74.3$

3 Efecto cuadrático, $y=0,0069 x^{2}-0,2732 x+3,0828, R^{2}=85,3$

4 Efecto cuadrático $y=0,0611 x^{2}-2,4719 x+28,098, R^{2}=0,9594$

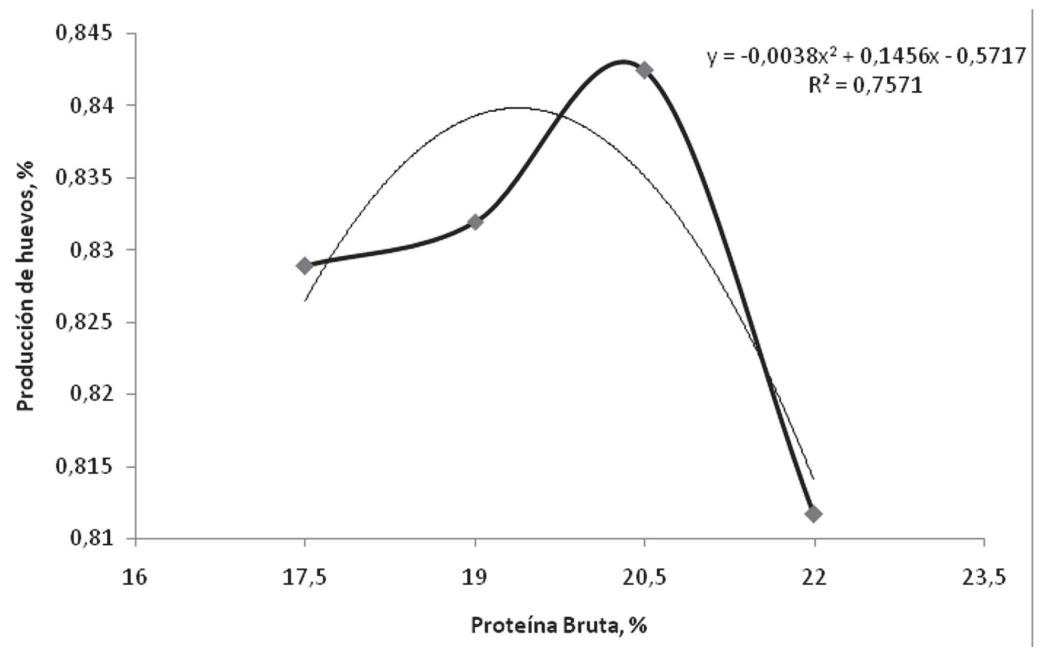

Figura 1. Producción de huevos en función al nivel de proteína 


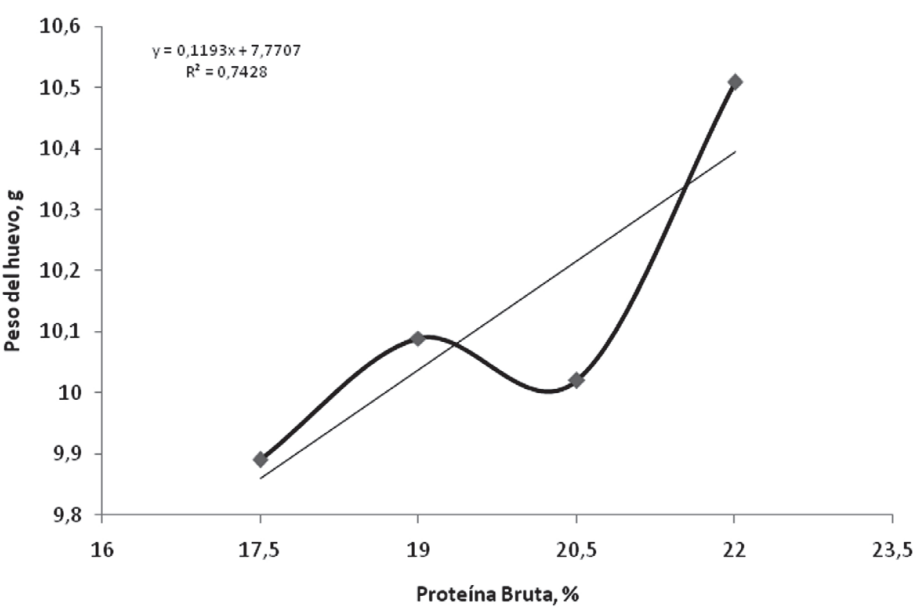

Figura 2. Peso del huevo en función al nivel de proteína

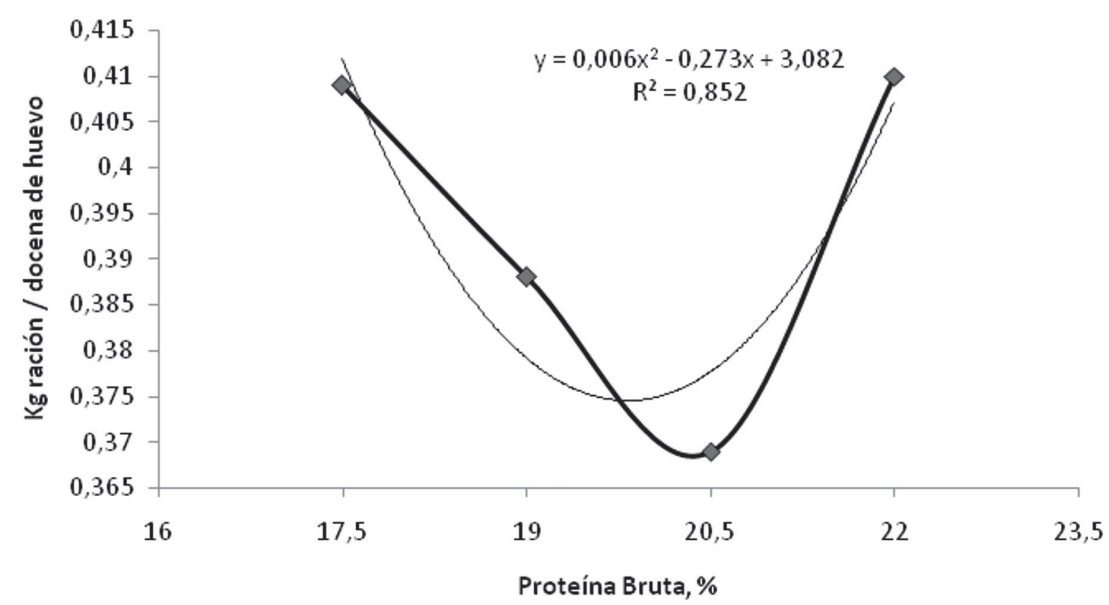

Figura 3. Conversión alimenticia, kg de ración/docena de huevos función al nivel de proteína

estimar en 20,23\% el requerimiento de PB para mejor conversión relacionada con la masa de huevo.

\section{Discusión}

La inexistencia de interacción entre los niveles de energía y de proteína, indica que los niveles de proteína y de energía actuaron de manera independiente, haIlazgos semejantes fueron reportados por Freitas et al., (2005).

Los resultados obtenidos de producción de huevos corroboran los resultados de Pinto et al., (2002), que constataron efecto cuadrático de los niveles de proteína sobre la producción de huevos, alcanzando un nivel máximo de $22,42 \%$ de proteína. Por otro lado, Moura et al., (2008) obtuvieron mayor producción de huevos, entre 85,9 y $93,9 \%$, trabajando con dietas de diferentes densidades energéticas.

Estos resultados se explican por la concentración y el consumo de proteína en la ración, los cuales establecen una correlación positiva con la producción de huevos, aunque la producción de huevos es una característica que depende de la línea genética del ave, la cantidad proteína suministrada contribuye a maximizar la postura.

El valor estimado por regresión polinomial del requerimiento de proteína $(19,16 \%)$ difiere del requerimiento propuesto por RNC (1994) de $20 \%$ y del sugerido por Rostagno et al., (2011) de 19,94\%, para un consumo de ración de 24,78 g y 2800 kcal EM/kg. 


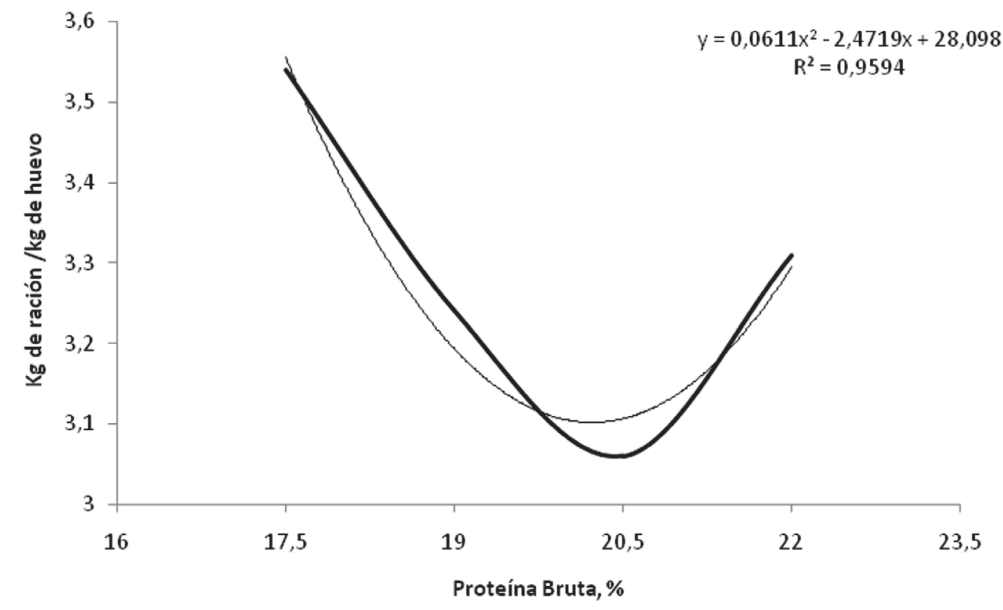

Figura 4. Conversión alimenticia $\mathrm{kg}$ de ración/ kg de huevo, en función al nivel de proteína

Los resultados de peso de los huevos por efecto de los niveles de proteína, se explican porque la ingestión de este nutriente atiende el requerimiento para la producción de huevos más pesados, indicando una relación directa entre la cantidad de proteína en la dieta con el peso del huevo.

Estos resultados difieren de los encontrados por Moura et al., (2008) que no constataron diferencias significativas para peso y masa de huevo.

Los resultados de consumo diario de ración, son posibles de explicar a partir de la teoría quimiostática, es decir, que las codornices regulan el consumo, según las necesidades de energía. Sin embargo, otros factores pueden influenciar el consumo, como el peso corporal, fase de postura, crecimiento, ambiente de cría (Albino y Barreto, 2003).

Los resultados de consumo de ración difieren de los valores Barreto et al., (2007), que encontraron una reducción linear con el incremento de los niveles de energía metabolizable en la ración de 2650 a 3050 kcal EM, sugiriendo la capacidad del ave de ajustar el consumo de ración en función de los nutrientes exigidos para máximo desempeño

Los resultados de conversión alimenticia (kg de ración/ docena de huevos y $\mathrm{kg}$ de ración/ $\mathrm{kg}$ de huevo), se explican por su relación directa con el consumo de ración y la producción obtenida, indicando que los tratamientos de mejor conversión alimenticia son a su vez los de mayor postura, corroborando, que el peso y la masa de huevo son influenciadas por la ingestión diaria de proteína en aves de postura (Pinto et al., (2002).
En conclusión, la exigencia de proteína bruta para máxima producción de huevos de codornices japonesas en fase de postura en condiciones de clima cálido, se estima en $19,16 \%$, valor próximo al de mayor producción de huevos, que se obtuvo con $20,5 \%$ de proteína bruta y $2750 \mathrm{kcal}$ EM/kg

\section{Agradecimientos}

A la Dirección General de Investigaciones de la Universidad de los Llanos, Colombia por la financiación de esta investigación.

\section{Referencias}

Albino LFT, Barreto SLT. 2003. Codornas: criação de codornas para produção de ovos e carne. Viçosa: Aprenda fácil. 289p.

Barreto SLT, Quirino BJS, Brito CO, Umigi RT, Araujo MS, Coimbra JSR, Rojas EEG, Freitas JF, Reis RS. Níveis de energia metabolizável para codornas japonesas na fase inicial de postura, $\mathrm{R}$ Bras Zootec, 2007;36(1): 79-85.

Costa FGP, Rodrigues VP, Goular CC, Lima Neto RC, Souza JG, Silva JHV. Exigências de lisina digestível para codornas japonesas na fase de postura, R Bras Zootec, 2008; 37(12): 2136-2140.

Florez VL, Ospina GLH. Productora de huevos de codornices Kepau S.A.S. (Trabajo de grado) Institución Universitaria CEIPA, Sabaneta, 2010, 110p.

Freitas AC, Fuentes MFF, Freitas ER, Sucupira FS, Oliveira BCM. Efeito de Níveis de Proteína Bruta e de Energia Metabolizável na Dieta sobre o Desempenho de Codornas. R Bras Zootec, 2005; 34(4): 838-846.

Instituto Geográfico Agustín Codazi, IGAC. 2007. Mapas de Colombia (mapa topográfico). 
Moura GS, Barreto SLT, Donzele JL, Hosoda LR, Pena GM, Angelini MS. Dietas de diferentes densidades energéticas mantendo constante a relação energia metabolizável: nutrientes para codornas japonesas em postura. R Bras Zootec, 2008; 37(9): 1628-1633.

Moura AMA, Fonseca JB, Takata FN, Rabello CBV, Lombardi CT. Determinação da energia metabolizável de alimentos para codornas japonesas em postura, Arq Bras Med Vet Zootec, 2010; 62(1):178-183.

Murakami AE. Garcia ERM. Pontos Críticos na Criação de codornas. 2007. IV CURSO DE ATUALIZAÇÃO EM AVICULTURA PARA POSTURA COMERCIAL. Jaboticabal: FCAV/UNESP, Jaboticabal, p. 41-53.

National Research Council - NRC.1994. Nutrient requirements of poultry. Washington, D.C. p.44-45.
PenzJr AM, Kessler AM, Brugallil. 1999.Novos conceitos de energia para aves. In: SIMPÓSIO INTERNACIONAL SOBRE NUTRIÇÃO DE AVES, 1999, Campinas. Anais...Campinas: FACTA. p.1-24.

Pinto R, Ferreira AS, Albino LFT, Gomes PC, Vargas Jr JGR. Níveis de Proteína e Energia para Codornas Japonesas em Postura. R Bras Zootec, 2002; 31(4): 1761-1770.

Rostagno, H. 2011. Composição de Alimentos e Exigências Nutricionais, 3a EdiçãoUniversidade Federal de Viçosa - Departamento de Zootecnia, 252p

Silva JHV, Ribeiro MLG. 2001. Tabela nacional de exigência nutricional de codornas. Bananeiras, PB. DAP-CFT-UFPB. 19p.

Rizzo PV, Guandolini GC, Amoroso L, Malheiros RM, Moraes VMB. Triptófano na alimentação de codornas japonesas nas fases de recria e postura. R Bras Zootec, 2008; 37(6): 1017-1022. 